\section{VIRUS ENTÉRICOS HUMANOS EN ALIMENTOS: DETECCIÓN Y MÉTODOS DE INACTIVACIÓN}

\author{
Walter Randazzo \\ Universidad de Valencia \\ ORCID iD: https://orcid.org/0000-0002-7433-149X \\ walter.randazzo@uv.es \\ Irene Falcó \\ Instituto de Agroquímica y Tecnología de Alimentos \\ Consejo Superior de Investigaciones Científicas \\ ORCID iD: https://orcid.org/0000-0002-4036-3274 \\ irene.falco@iata.csic.es \\ Alba Pérez-Cataluña \\ Instituto de Agroquímica y Tecnología de Alimentos \\ Consejo Superior de Investigaciones Científicas \\ ORCID iD: https://orcid.org/0000-0002-4784-8346 \\ alba.perez@iata.csic.es \\ Gloria Sánchez \\ Instituto de Agroquímica y Tecnología de Alimentos \\ Consejo Superior de Investigaciones Científicas \\ ORCID iD: https://orcid.org/0000-0001-7022-661X \\ gloriasanchez@iata.csic.es
}

Cómo citar este artículo/Citation: Randazzo, W., Falcó, I., PérezCataluña, A. y Sánchez, G. (2020). Virus entéricos humanos en alimentos: detección y métodos de inactivación. Arbor, 196 (795): a539. https://doi.org/10.3989/arbor.2020.795n1003

Recibido: 26 febrero 2019. Aceptado: 29 octubre 2019.

RESUMEN: Los principales patógenos víricos que podemos adquirir ingiriendo alimentos contaminados son los norovirus, el virus de la hepatitis A y el virus de la hepatitis E que se propagan principalmente a través de la vía fecal oral. En los últimos años, la incidencia de brotes de transmisión alimentaria causados por estos patógenos ha experimentado un aumento considerable, en parte debido al comercio globalizado y a los cambios en los hábitos de consumo. Las matrices alimentarias que mayor riesgo representan para el consumidor son los moluscos bivalvos, vegetales de IV gama, frutas tipo baya y platos listos para comer. Actualmente las técnicas moleculares son las más habituales para la detección de estos patógenos en alimentos, aunque todavía existen dudas acerca del significado de la presencia de estos genomas víricos en términos de seguridad alimentaria. La infectividad de estos patógenos en alimentos viene también determinada por su elevada persistencia ambiental y por su resistencia a los tratamientos aplicados para la conservación de los alimentos.

PALABRAS CLAVE: virus entéricos; seguridad alimentaria; inactivación vírica; compuestos virucidas; envases virucidas; métodos moleculares; metagenómica.

\section{HUMAN ENTERIC VIRUSES IN FOOD: DETECTION AND INACTIVATION METHODS}

Copyright: (C) 2020 CSIC. Este es un artículo de acceso abierto distribuido bajo los términos de la licencia de uso y distribución Creative Commons Reconocimiento 4.0 Internacional (CC BY 4.0).

ABSTRACT: The main viral pathogens that can be acquired by ingesting contaminated food are norovirus, and hepatitis $A$ and $E$ viruses that are spread mainly through the oral-faecal route. In recent years, the incidence of foodborne outbreaks caused by these pathogens has increased considerably, partly due to globalised trade and changes in consumption habits. Foodborne outbreaks caused by enteric viruses are mainly associated with bivalve molluscs, fresh-cut vegetables, berries and ready-to-eat meals. Molecular-based techniques are currently used for the detection of these pathogens in food, although there are still doubts about the significance of the presence of viral genomes in terms of food safety. The infectivity of these pathogens in food is also driven by their high persistence in the environment and to their resistance to treatments commonly applied by the food industry.

KEYWORDS: foodborne viruses; food safety; viral inactivation; antiviral compounds; antiviral packaging; molecular methods; metagenomics. 


\section{INTRODUCCIÓN}

Los virus de transmisión alimentaria, o virus entéricos, se encuentran entre los principales riesgos sanitarios asociados al consumo de alimentos, y por ende repercuten en la seguridad alimentaria. Recientemente la organización mundial de la salud ha elaborado un informe según el cual anualmente se producen 120 millones de casos de gastroenteritis causada por norovirus humanos (NoV) (véase World Health Organization). Los virus entéricos son responsables de diversas patologías: desde gastroenteritis, normalmente leves, hasta patologías más graves como hepatitis agudas, miocarditis o incluso meningitis o encefalitis aséptica. En los últimos años, se ha producido un aumento en el número de brotes de transmisión alimentaria causados por estos patógenos. Esto supone un importante problema de salud pública, ocasionando graves complicaciones sanitarias en algunos grupos de población, como personas inmunodeprimidas o ancianos, además de tener importantes repercusiones económicas.

Los virus que más preocupan hoy en día en el ámbito de la seguridad alimentaria son los NoV, el virus de la hepatitis A (VHA), y más recientemente el virus de la hepatitis $E(V H E)$ que causan cuadros de hepatitis agudas, y este último en algunos casos puede llegar a evolucionar hasta hepatitis crónica. Además, las embarazadas con hepatitis $E$, presentan mayor riesgo de insuficiencia hepática aguda y de muerte propia y del feto. En el tercer trimestre del embarazo se han registrado tasas de letalidad de hasta un $20-25 \%$.

Otros virus causantes de gastroenteritis como los sapovirus, rotavirus, adenovirus, astrovirus, Aichi virus, parvovirus y picobirnavirus han sido esporádicamente asociados al consumo de alimentos contaminados.

Según los últimos datos publicados en Estados Unidos y en Europa, los NoV son los responsables etiológicos del 36 \% y 7,8 \% de los brotes de transmisión alimentaria, y se sitúan entre los cinco patógenos responsables de las enfermedades de transmisión alimentaria que suponen un mayor coste económiCo (EFSA and ECDC, 2018). En Europa, en el periodo 2017-2018 el sistema de alerta rápida para alimentos y piensos ha informado de 86 alertas de contaminación por virus entéricos (https://webgate.ec.europa. eu/rasff-window/portal/?event=SearchForm\&cleanS earch=1), 81 (94\%) de ellas causadas por NoV y 5 (6\%) por VHA. Los alimentos involucrados han sido mayoritariamente los moluscos bivalvos (73\%), junto con los frutos rojos (23\%) y las hortalizas (4\%).
Los virus entéricos son transmitidos principalmente por la vía fecal-oral y, por tanto, pueden estar potencialmente presentes en alimentos que hayan sufrido contaminación directa con materia fecal, o a través de aguas contaminadas. Los principales alimentos involucrados en infecciones víricas transmitidas por alimentos son los moluscos bivalvos, las verduras y ensaladas, las frutas tipo baya, así como también los alimentos preparados y listos para su consumo que hayan sido contaminados por manipulación incorrecta después de su preparación o cocinado. Por otra parte, recientemente se ha demostrado un aumento de la incidencia de casos de hepatitis $\mathrm{E}$ asociados al consumo de carne cruda o poco cocinada de cerdo y jabalí procedente de animales infectados (Kupferschmidt, 2016).

La importancia de los virus entéricos en el campo de la seguridad alimentaria se pone de manifiesto por el interés mostrado por distintos organismos internacionales. Entre ellos destaca la comisión del Codex Alimentarius, que publicó un documento sobre la importancia de los virus de transmisión alimentaria. En dicho documento se pone de manifiesto la importancia de desarrollar ciertos aspectos científicos y técnicos con la finalidad de reducir las infecciones víricas transmitidas por los alimentos. En el plan estratégico a seguir se menciona la necesidad de desarrollar métodos rápidos de diagnóstico, estudios para establecer la correlación entre infectividad y detección molecular, y finalmente estudios sobre la efectividad de los procesados alimentarios para la inactivación de virus entéricos (CX/FH 08/40/9). En este sentido, la Agencia Europea de Seguridad Alimentaria (EFSA) también ha publicado diversas directrices sobre la relevancia y el control de virus en alimentos; en línea con las directrices sobre principios generales de higiene para el control de virus en alimentos (CX/FH 10/42/5) elaboradas por la comisión Codex. En estos documentos se subraya que el control de los riesgos en alimentos debe empezar durante la producción agrícola o animal y continuar durante toda la cadena alimentaria ("de la granja a la mesa"). En este aspecto, los virus de transmisión alimentaria requieren especial atención debido a que se comportan de manera diferente a los patógenos bacterianos, y a que las medidas de control implementadas actualmente en la industria alimentaria no han sido evaluadas o no son efectivas para la inactivación de virus entéricos. En el campo de la seguridad microbiológica de los alimentos es necesario, por tanto, conocer el riesgo real que supone la presencia de los virus entéricos en los alimentos, así como aquellas condiciones que garanticen la seguridad microbiológica del alimento. 


\section{INACTIVACIÓN DE VIRUS EN ALIMENTOS}

Para poder controlar la contaminación vírica de alimentos, es necesario el desarrollo de metodologías que permitan determinar la reducción de virus infecciosos presentes en alimentos después de aplicar tratamientos de conservación. Este hecho pasa por el uso de cultivos celulares o modelos animales, lo cual restringe mucho el rango de virus a estudiar. Esto es especialmente importante para los NoV y las cepas silvestres del VHA y del VHE, que no replican fácilmente en cultivos celulares y por ende dificultan los estudios de inactivación. Por ello, el uso de cepas adaptadas a cultivo celular o virus sustitutos, como el calicivirus felino (FCV), el norovirus murino (MNV) y el virus Tulane, se han utilizado de forma extensiva para este tipo de estudios. Para realizar este tipo de trabajos, de manera general, se llevan a cabo ensayos donde se inoculan concentraciones conocidas de virus en la muestra, observando la reducción de dicha concentración después del tratamiento.

\subsection{Eficacia de los tratamientos de conservación uti- lizados por la industria alimentaria}

Los virus entéricos son generalmente muy resistentes a las condiciones ambientales y a los tratamientos de conservación, y pueden persistir durante largos periodos de tiempo como partículas infecciosas en alimentos más allá de la vida útil del alimento. Los tratamientos de conservación utilizados por la industria alimentaria pueden inactivar a los virus entéricos, pero existen diferencias entre un virus y otro en cuanto a su resistencia a estos procesos. Además, las características intrínsecas de la matriz alimentaria, así como la presencia de materia orgánica, también influyen en el grado de resistencia a los tratamientos (Randazzo, D’Souza y Sanchez, 2018; Sánchez, 2015).

La eficacia de los tratamientos de inactivación tanto químicos como térmicos, como la esterilización, el escaldado o la pasteurización, sobre la infectividad de los virus entéricos varía dependiendo de la matriz alimentaria y del (sub)tipo del virus. Evidencias de la respuesta virus -y genogrupo- dependiente a inactivaciones mediante alcoholes y cloro han sido confirmadas utilizando un novedoso sistema de replicación en cultivo de NoV (Costantini et al., 2018). Este estudio demuestra que tratamientos con $70 \%$ de etanol e isopropanol durante cinco minutos no son suficientes para inactivar NoV genogrupo II (GII), mientras que tratamientos con concentraciones por encima de $50 \mathrm{ppm}$ de cloro consiguen inactivar por completo NoV GII.
Diferentes estudios en moluscos bivalvos indican que son necesarias grados de cocción en que se garantice una temperatura interna de 90 ㅇ durante un minuto y medio para inactivar completamente los virus entéricos. Sin embargo, los tratamientos térmicos más suaves, como pueden ser la cocción al vapor o a la parrilla de moluscos bivalvos y verduras, no son adecuados para inactivar completamente a estos patógenos (Randazzo, D'Souza y Sanchez, 2018).

En productos cárnicos, diversos estudios han demostrado que el VHE se mantiene infeccioso después de un tratamiento de una hora a 56으. y que hay que aplicar temperaturas de cocción de 71으 C durante veinte minutos para inactivarlo. Desde un punto de vista práctico, se ha establecido que la carne hervida a 191ㅇ C durante cinco minutos (asegurando una temperatura interna de $71^{\circ} \mathrm{C}$ ) inactiva completamente al VHE (Ricci et al., 2017)). Por otro lado, diversos estudios demuestran que tratamientos a menor temperatura pero más prolongados en el tiempo son más eficaces que tratamientos a altas temperaturas pero con tiempos cortos de exposición, por lo que los procesos convencionales de pasteurización parecerían ser más efectivos que los de pasteurización relámpago.

Mucho menos efectivos resultan los tratamientos convencionales no térmicos, como la depuración de moluscos bivalvos o el lavado de vegetales y bayas. Por ejemplo, la depuración de mejillones durante siete días solo reduce la infectividad de HAV en 1,5 órdenes logarítmicos, mientras que después de veinte días de depuración se seguían detectando NoV infecciosos (Randazzo, D’Souza y Sanchez, 2018; Sánchez, 2015). Por otra parte, el lavado de alimentos resulta bastante ineficaz ya que el tratamiento es dependiente tanto de la superficie del alimento como de la localización de la contaminación en el mismo, siendo demostrada la internalización de virus entéricos en distintas hortalizas (DiCaprio, Ma, Purgianto, Hughes y Li, 2012). La aplicación de nuevas tecnologías alternativas como las altas presiones han demostrado ser eficaces para la inactivación de virus entéricos a presiones por encima de los $400 \mathrm{MPa}$, que por otro lado afectan significativamente a la calidad organoléptica de los productos procesados (Randazzo, D'Souza y Sanchez, 2018; Sánchez, 2015).

Para garantizar la calidad de los alimentos, alargar su vida útil y dar respuesta a una demanda cada vez mayor de productos más naturales, la industria alimentaria busca alternativas al uso de aditivos químicos. Los compuestos naturales han ganado un gran interés no solo por parte de los consumidores, sino también 
de investigadores y de la industria alimentaria debido a que son compuestos GRAS (generally recognized as safe), y a que el crecimiento del denominado "consumo verde" estimula su uso representando una alternativa natural y barata frente a los aditivos químicos. Numerosos compuestos bioactivos naturales, aceites esenciales, extractos de plantas y algas, han sido evaluados frente a distintos virus entéricos, mostrando un gran potencial virucida (Randazzo, D'Souza y Sanchez 2018; Sánchez, 2015). Debido al gran potencial de estos compuestos naturales, se están llevando a cabo investigaciones sobre su potencial uso en la industria alimentaria (véase tabla 1). Así pues, el lavado de diferentes vegetales con extractos de aloe vera, semillas de uva, té verde, carvacrol u otros aceites esenciales han sido capaces de reducir la presencia de virus entéricos en la superficie de algunos vegetales. La desinfección de superficies de contacto alimentario es importante ya que es una de las vías más frecuentes de contaminación cruzada; por eso el extracto de té verde o de semilla de uva han sido aplicados como desinfectantes naturales en superficies de acero, cristal o plástico mostrando una eficacia de hasta el $99 \%$ en la reducción de la infectividad del MNV y VHA (Li et al., 2012; Randazzo, Falcó, Aznar y Sánchez, 2017).

Una de las aplicaciones más novedosas de estos compuestos es su incorporación en polímeros para su uso como envases y recubrimientos antimicrobia- nos (Randazzo, Fabra, Falcó, López-Rubio y Sánchez, 2018). Este tipo de aplicaciones se ha evaluado principalmente frente a bacterias y hongos, pero muy pocos estudios han evaluado su eficacia frente a virus entéricos. El cinamaldehído, el extracto de té verde y el de semilla de uva son algunos de los compuestos naturales incorporados en biopolímeros y que han resultado ser muy efectivos para la inactivación de virus entéricos (Amankwaah, 2013; Fabra et al., 2016; Falcó et al., 2018; Falcó, Randazzo, Rodríguez-Díaz et al., 2019; Randazzo, Fabra, Falcó, López-Rubio. y Sánchez, 2018). El extracto de té verde también ha sido incorporado a matrices de alginato y carragenatos para ser aplicado como recubrimiento comestible en frutas susceptibles de sufrir contaminación vírica como son fresas, frambuesas o arándanos (Falcó, Randazzo, Sánchez et al., 2019; Falcó, Randazzo, Sánchez, LópezRubio y Fabra, 2019).

Asimismo, el potencial virucida del extracto de té verde o de semillas de uva ha sido evaluado in vitro en modelos alimentarios y bajo condiciones gástricas (Joshi, Su y D'Souza, 2015). Aunque se trata de estudios preliminares, estos prometedores resultados podrían ser el inicio de la formulación de nutracéuticos o alimentos funcionales con propiedades antivirales que incorporen estos compuestos en su formulación, asegurando entre otras cosas la salud de los consumidores.

Tabla 1. Uso de compuestos naturales en diferentes aplicaciones industriales para el control de virus entéricos

\begin{tabular}{|c|c|c|c|c|c|}
\hline & \multirow[t]{2}{*}{ Aplicaciones } & & \multirow[t]{2}{*}{ Compuesto natural } & \multicolumn{2}{|c|}{ Reducciones (\%) } \\
\hline & & & & MNV & HAV \\
\hline \multirow{7}{*}{$\begin{array}{l}\text { Desinfectante } \\
\text { natural }\end{array}$} & \multirow{2}{*}{ Superficies de contacto } & & Extracto de té verde & 99 & 99,9 \\
\hline & & & Extracto de semilla de uva & 50 & - \\
\hline & \multirow{5}{*}{ Superficies vegetales } & & Extracto de té verde & 95 & 99,9 \\
\hline & & & Extracto de semilla de uva & 90 & 92 \\
\hline & & & Extracto de aloe vera & 82 & - \\
\hline & & & Extracto de níspero & 62 & - \\
\hline & & & Carvacrol & 98,2 & - \\
\hline \multirow{6}{*}{$\begin{array}{l}\text { Materiales } \\
\text { virucidas }\end{array}$} & \multirow{3}{*}{ Films } & & Cinamaldehído & 99,8 & 50 \\
\hline & & & Extracto de té verde & 40 & 35 \\
\hline & & & Extracto de semilla de uva & 15 & 22 \\
\hline & \multirow{3}{*}{$\begin{array}{l}\text { Recubrimientos } \\
\text { comestibles }\end{array}$} & Fresas & & 75 & 28 \\
\hline & & Frambuesas & Extracto de té verde & 50 & 18 \\
\hline & & Arándanos & & 99,9 & 90 \\
\hline
\end{tabular}

Fuente: elaboración propia. 


\section{MÉTODOS PARA LA DETECCIÓN DE VIRUS EN ALIMENTOS}

La detección de virus entéricos es especialmente compleja ya que la mayoría de estos patógenos no replican fácilmente en cultivos celulares, en general se encuentran en concentraciones muy bajas, la contaminación vírica no es uniforme y los virus entéricos pueden encontrarse internalizados en verduras de hoja.

La detección de virus en alimentos se ha visto incrementada exponencialmente en los últimos años, estableciéndose métodos de detección basados en técnicas moleculares, principalmente RT-qPCR cuya normalización (ISO 15216-1:2017 e ISO/TS 15216-2:2013) y validación (Lowther et al., 2019) en determinadas matrices (agua embotellada, superficie de alimentos, moluscos bivalvos, frutos rojos y verduras de hoja verde) han sido recientemente publicadas para NoV GI y GII, y VHA. Desafortunadamente, hasta la fecha no existen métodos estandarizados para la detección y cuantificación del VHE en muestras de alimentos, a pesar de ser una de las prioridades establecidas recientemente por la agencia europea de seguridad alimentaria (Ricci et al., 2017).

El análisis de virus en alimentos consiste en una etapa inicial de separación de los virus de la matriz alimentaria, seguida de la concentración de virus y purificación, diseñada para reducir el volumen de muestra y eliminar algunos de los compuestos de la matriz mientras que simultáneamente se recupera la mayor parte de los virus contaminantes (Bosch et al., 2011). Posteriormente se realiza la extracción de ácidos nucleicos, y detección y cuantificación mediante RT-qPCR. Alternativamente la PCR digital, que no depende de materiales de referencia o estándares para la cuantificación de la muestra, se ha empezado a utilizar en el campo de la virología de alimentos (Fraisse et al., 2017; Persson, Eriksson, Lowther, Ellström y Simonsson, 2018; Varela, Monteiro, Rivadulla, Santos y Romalde, 2018).

La metodología descrita en las ISO 15216-1:2017 e ISO/TS 15216-2:2013 incluye diversos controles para evaluar la presencia de inhibidores y determinar la eficacia del proceso de extracción mediante el uso de un control de proceso, generalmente el mengovirus. Todo ello hace que el análisis de virus en alimentos tenga un coste económico elevado. A pesar de esto, el método ISO se está utilizando en laboratorios de control de aguas y alimentos; y actualmente diversos laboratorios nacionales han acreditado estos procedimientos por la entidad nacional de acreditación (ENAC). Además, en los últimos años estos procedimientos están siendo utilizados a nivel fronterizo para la inspección de alimentos de riesgo por contaminación vírica aunque a día de hoy no hay legislación que regule los niveles permitidos de virus en alimentos. En esta línea la EFSA ha organizado un estudio para determinar los niveles de NoV en moluscos bivalvos con el fin de poder establecer los límites permitidos para norovirus (EFSA, 2019).

Por otro lado, estos métodos son rápidos, sensibles y altamente específicos, pero al detectar genomas no son capaces de diferenciar entre virus infecciosos y no infecciosos, y ello dificulta enormemente la interpretación de un resultado positivo en términos de análisis de riesgo. Con el fin de obtener una mejor correlación entre la detección por RT-qPCR y la infectividad de la muestra se han investigado distintas aproximaciones: i) recuperación de NoV potencialmente infecciosos unidos selectivamente a mucina gástrica porcina; ii) tratamientos con nucleasas y enzimas proteolíticas antes de la extracción para eliminar cualquier señal de cápsides dañadas; iii) PCR de fragmentos largos; iv) tratamientos con reactivos de viabilidad, ya sea con un paso de fotoactivación (por ejemplo, propidio y etidio de monoazida, PMA o EMA) o sin fotoactivación (por ejemplo, compuestos de platino y paladio). Esta última aproximación, la PCR de viabilidad, se ha descrito para distintos virus entéricos inactivados por calor, tratamiento con cloro, luz ultravioleta o altas presiones (véase tabla 2), y en los últimos años se han utilizado para la detección de estos patógenos en muestras de contaminación natural, principalmente en muestras de agua residual, superficial o embotellada y en ostras (Fuster et al., 2016; López-Gálvez et al., 2018; Prevost et al., 2016; Randazzo, Khezri et al., 2018; Randazzo, Vasquez-García, Aznar y Sánchez, 2018). Aunque los pretratamientos con reactivos de viabilidad reflejan mejor los patrones de inactivación vírica, la correlación con la infectividad sigue sin ser absoluta, dependiendo del virus o del tratamiento de inactivación aplicado. A pesar de ello, incorporar estas metodologías en los análisis de rutina permitirá una cuantificación más precisa de los virus infecciosos presentes en los alimentos, constituyendo una herramienta muy útil para la evaluación de riesgos.

\section{NUEVAS HERRAMIENTAS MOLECULARES PARA EL ESTUDIO DE VIRUS EN ALIMENTOS}

En la última década se ha extendido el uso de tecnologías de secuenciación masiva para el estudio de la diversidad vírica, o estudio de viromas. Los estudios metagenómicos pueden utilizarse para el control tanto de los ambientes relacionados con la producción de alimentos (industria alimentaria, acuicultura...), como para el control de los propios alimentos y de los posibles brotes producidos por su consumo que nos per- 
Tabla 2. PCR de viabilidad para la detección de virus potencialmente infecciosos

\begin{tabular}{|c|c|c|c|c|}
\hline Virus & Tratamiento & Reactivo/surfactante & Matriz & Referencias \\
\hline \multirow[t]{10}{*}{ NoV } & $\begin{array}{l}72^{\circ} \mathrm{C}, 5 \mathrm{~min} \\
90^{\circ} \mathrm{C}, 5 \mathrm{~min}\end{array}$ & PMA & & \multirow{7}{*}{$\begin{array}{c}\text { Revisado por } \\
\text { Randazzo, D'Souza y } \\
\text { Sanchez (2018) }\end{array}$} \\
\hline & Calor & PMA & Heces & \\
\hline & Cloro & & & \\
\hline & Cloro & $\mathrm{PMA} / \mathrm{INCl}$ & & \\
\hline & $65-85^{\circ} \mathrm{C}, 2 \mathrm{~min}$ & PMA & Heces, espinacas & \\
\hline & \multirow[t]{2}{*}{$99^{\circ} \mathrm{C}, 5 \mathrm{~min}$} & \multirow[t]{2}{*}{ PMAxx/Tritón } & Heces, espinacas, lechuga & \\
\hline & & & Moluscos bivalvos & \\
\hline & $72^{\circ} \mathrm{C}, 2 \mathrm{~min}$ & \multirow{2}{*}{$\mathrm{PtC}_{14}$} & \multirow{2}{*}{ Heces } & \multirow{2}{*}{ Fraisse et al. (2018) } \\
\hline & $80^{\circ} \mathrm{C}, 5 \mathrm{~min}$ & & & \\
\hline & Dióxido de cloro & PMAxx/Tritón & Heces, agua de riego & $\begin{array}{l}\text { López-Gálvez et al. } \\
\text { (2018) }\end{array}$ \\
\hline \multirow[t]{7}{*}{ HAV } & $99^{\circ} \mathrm{C}, 5 \mathrm{~min}$ & \multirow[b]{2}{*}{ PMA } & \multirow{2}{*}{ Suspensión cultivo celular } & \multirow{2}{*}{$\begin{array}{c}\text { Sánchez, Elizaquível y } \\
\text { Aznar (2012) }\end{array}$} \\
\hline & $500 \mathrm{MPa}, 15 \mathrm{~min}$ & & & \\
\hline & Calor & EMA/IGEPAL & Suspensión cultivo celular & $\begin{array}{l}\text { Coudray-Meunier, } \\
\text { Fraisse, Martin-Latil, } \\
\text { Guillier y Perelle } \\
\text { (2013) }\end{array}$ \\
\hline & \multirow{2}{*}{$5 \min 99^{\circ} \mathrm{C}$} & \multirow{2}{*}{ PMA/Tritón } & Agua de lavado & \multirow{2}{*}{$\begin{array}{l}\text { Moreno, Aznar y } \\
\text { Sánchez (2015) }\end{array}$} \\
\hline & & & Vegetables & \\
\hline & Calor & PMA/Tritón & Suspensión cultivo celular & Fuster et al. (2016) \\
\hline & Calor & PMAxx/Tritón & $\begin{array}{c}\text { Moluscos bivalvos y } \\
\text { vegetales }\end{array}$ & $\begin{array}{c}\text { Randazzo, Khezri et al. } \\
\text { (2018) }\end{array}$ \\
\hline \multirow[t]{2}{*}{ HEV } & $95^{\circ} \mathrm{C}, 15 \mathrm{~min}$ & \multirow[b]{2}{*}{$\mathrm{PICl}_{4}$} & \multirow[b]{2}{*}{ Heces } & \multirow{2}{*}{$\begin{array}{c}\text { Randazzo, Vasquez- } \\
\text { García, Aznar y } \\
\text { Sánchez (2018) }\end{array}$} \\
\hline & $500 \mathrm{MPa}, 15 \mathrm{~min}$ & & & \\
\hline
\end{tabular}

Fuente: elaboración propia.

mitirían conocer tanto las posibles cepas responsables de brotes como las tendencias en la aparición de determinados virus y la detección de nuevos virus emergentes (Nieuwenhuijse y Koopmans, 2017). El uso de la secuenciación masiva en el estudio de brotes víricos relacionados con el consumo de agua y alimentos permite, además, la detección de todos los virus mediante un único protocolo y proporciona información adicional para el trazado epidemiológico. Su uso en la cadena de producción alimentaria también presenta un gran potencial, debido a la elevada sensibilidad y rango de detección (Aarestrup et al., 2012). En la tabla 3 se resumen los diferentes estudios de metagenómi- ca vírica en alimentos que se han realizado hasta la fecha. Algunos de ellos se han dirigido únicamente a la secuenciación de virus de ADN (Park et al., 2011) o ARN (Yang et al., 2017), mientras que otros han analizado la presencia de virus con ambos tipos de material genético (Aw, Wengert y Rose, 2016; Bartsch, Höper, Mäde y Johne, 2018; Fernandez-Cassi et al., 2017).

Sin embargo, las técnicas de secuenciación masiva todavía presentan ciertas dificultades relacionadas con la preparación y secuenciación de las muestras, el análisis de los datos y la interpretación de los mismos (Nieuwenhuijse y Koopmans, 2017). El principal 
problema a la hora de preparar una muestra para el análisis del viroma reside en la necesidad de reducir el material genético de la porción no vírica de la muestra. En la actualidad, diferentes aproximaciones están siendo evaluadas para obtener una mayor purificación del material genético vírico, tales como el uso de diferentes protocolos de extracción (Conceição-Neto et al., 2015; Cotten et al., 2014) o el uso de sondas para capturar virus (Briese et al., 2015). La elección de la plataforma de secuenciación también supone un problema en la estandarización de los estudios de metagenómica de virus. La elección de dicha plataforma debe realizarse teniendo en cuenta tanto el coste por nucleótido como el número de secuencias y el tamaño de estas. Una vez obtenidas las secuencias, el siguiente aspecto que hay que tener en cuenta es el análisis de los resultados. En este aspecto, tanto la infraestructura necesaria como el uso de un determinado programa de ensamblaje y la asignación de las secuencias suponen un problema en estos estudios. Por un lado, el análisis del elevado número de secuencias que proporcionan las técnicas de secuenciación masiva supone una fuerte inversión económica. Además, este análisis requiere personal especializado que sepa manejar diferentes programas y plataformas informáticas. Por último, la asignación de estos metagenomas a un determinado grupo vírico depende de las bases de datos utilizadas. En este aspecto, el mayor problema reside en la presencia de secuencias mal anotadas en algunas bases de datos o en que estas bases de datos están incompletas. Es por ello que la anotación de los metagenomas quedará supeditada al uso de la base de datos, teniendo que elegir entre bases de datos pequeñas y de alta calidad que proporcionen un menor número de resultados, o grandes bases de datos pero de menor calidad que proporcionarán un mayor número de resultados. Por ello, el uso de estos resultados debe realizarse con discreción cuando sean utilizados para aplicaciones de vigilancia y diagnóstico (Nieuwenhuijse y Koopmans, 2017). Además, los resultados obtenidos deben interpretarse teniendo en cuenta tanto el contenido vírico típico de la muestra de estudio como la capacidad infectiva del mismo, ya que la presencia de un fragmento de determinado genoma vírico no siempre implica la capacidad de infección del mismo. Todos estos aspectos técnicos evidencian la necesidad de mejorar y estandarizar los métodos utilizados en los estudios víricos mediante secuenciación masiva.

\section{BIBLIOGRAFÍA}

Aarestrup, F. M., Brown, E. W., Detter, C., Gerner-Smidt, P., Gilmour, M. W., Harmsen, D. [...] y Schlundt, J. (2012). Integrating genome-based informatics to modernize global disease monitoring, information sharing, and response. Emerging Infectious Diseases, 18 (11), e1. https://doi.org/10.3201/ eid/1811.120453

Amankwaah, C. (2013). Incorporation of selected plant extracts into edible chitosan films and the effect on the antiviral, antibacterial and mechanical properties of the material. [Tesis doctoral inédita]. The Ohio State University. Disponible en http://rave.ohiolink.edu/etdc/ view?acc_num=osu1366220367

Aw, T. G., Wengert, S. y Rose, J. B. (2016). Metagenomic analysis of viruses associated with field-grown and retail lettuce identifies human and animal viruses. International Journal of Food Microbiology, 223, pp. 50-56. https://doi. org/10.1016/j.ijfoodmicro.2016.02.008

Bartsch, C., Höper, D., Mäde, D. y Johne, R. (2018). Analysis of frozen strawberries involved in a large norovirus gastroenteritis outbreak using next generation sequencing and digital PCR. Food Mi- crobiology, 76, pp. 390-395. https://doi. org/10.1016/j.fm.2018.06.019

Bosch, A., Sánchez, G., Abbaszadegan, M., Carducci, A., Guix, S., Le Guyader, F. S. [...] y Sellwood, J. (2011). Analytical Methods for Virus Detection in Water and Food. Food Analytical Methods, 4 (1), pp. 4-12. https://doi.org/10.1007/ s12161-010-9161-5

Breitbart, M., Salamon, P., Andresen, B., Mahaffy, J. M., Segall, A. M., Mead, D., Azam, F. y Rohwer, F. (2002). Genomic analysis of uncultured marine viral communities. Proceedings of the National Academy of Sciences of the United States of America, 99 (22), pp. 14250-14255. https://doi.org/10.1073/ pnas. 202488399

Briese, T., Kapoor, A., Mishra, N., Jain, K., Kumar, A., Jabado, O. J. y lan Lipkina, W. (2015). Virome capture sequencing enables sensitive viral diagnosis and comprehensive virome analysis. MBio, 6 (5), e01491-15. https://doi.org/10.1128/mBio.01491-15

Conceição-Neto, N., Zeller, M., Lefrère, H., De Bruyn, P., Beller, L., Deboutte, W. [...] Matthijnssens, J. (2015). Modular approach to customise sample prepara- tion procedures for viral metagenomics: A reproducible protocol for virome analysis. Scientific Reports, 5 (1), 16532. https://doi.org/10.1038/srep16532

Costantini, V., Morantz, E. K., Browne, H., Ettayebi, K., Zeng, X. L., Atmar, R. L., Estes, M. K. y Vinjé, J. (2018). Human norovirus replication in human intestinal enteroids as model to evaluate virus inactivation. Emerging Infectious Diseases, 24 (8), pp. 1453-1464. https://doi. org/10.3201/eid2408.180126

Cotten, M., Oude Munnink, B., Canuti, M., Deijs, M., Watson, S. J., Kellam, P. y van der Hoek, L. (2014). Full genome virus detection in fecal samples using sensitive nucleic acid preparation, deep sequencing, and a novel iterative sequence classification algorithm. PLOS ONE, 9 (4), e93269. https://doi.org/10.1371/ journal.pone.0093269

Coudray-Meunier, C., Fraisse, A., MartinLatil, S., Guillier, L. y Perelle, S. (2013). Discrimination of infectious hepatitis $A$ virus and rotavirus by combining dyes and surfactants with RT-qPCR. BMC Microbiology, 13 (1), 216. https://doi. org/10.1186/1471-2180-13-216 


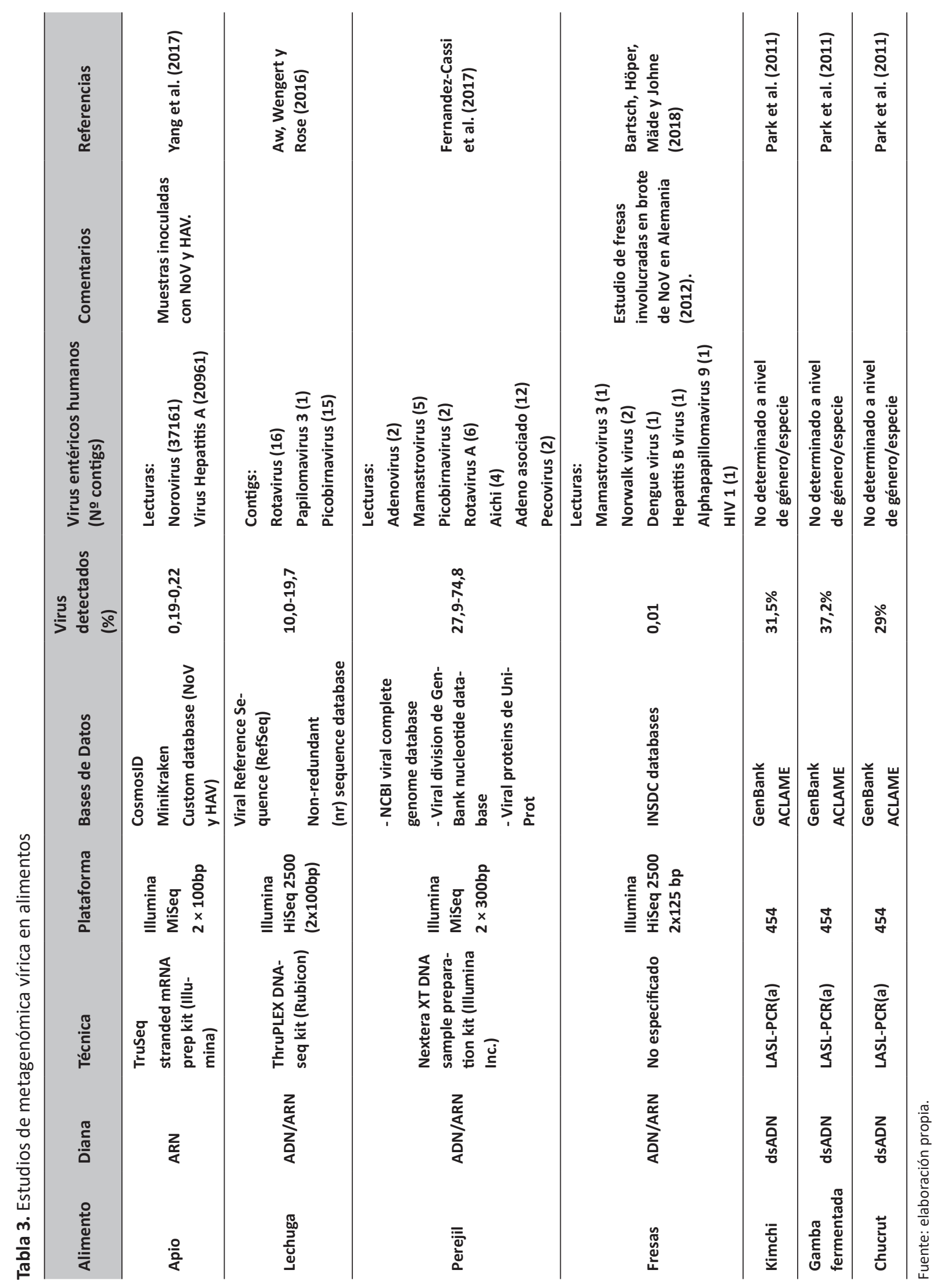


DiCaprio, E., Ma, Y., Purgianto, A., Hughes, J. y Li, J. (2012). Internalization and dissemination of human norovirus and animal caliciviruses in hydroponically grown romaine lettuce. Applied and Environmental Microbiology, 78 (17), pp. 6143-6152. https://doi.org/10.1128/ AEM.01081-12

European Food Safety Authority and European Centre for Disease Prevention and Control (EFSA and ECDC) (2018). The European Union summary report on trends and sources of zoonoses, zoonotic agents and food-borne outbreaks in 2017. EFSA Journal, 16 (12), e05500. https://doi.org/10.2903/j. efsa. 2018.5500

European Food Safety Authority (EFSA) (2019). Scientific report on analysis of the European baseline survey of norovirus in oysters. EFSA Journal, 17 (7), e05762. https://doi.org/10.2903/j. efsa.2019.5762

Fabra, M. J., Castro-Mayorga, J. L., Randazzo, W., Lagarón, J. M., López-Rubio, A., Aznar, R. y Sánchez, G. (2016). Efficacy of Cinnamaldehyde Against Enteric Viruses and Its Activity After Incorporation Into Biodegradable Multilayer Systems of Interest in Food Packaging. Food and Environmental Virology, 8 (2), pp. 125-132. https://doi.org/10.1007/ s12560-016-9235-7

Falcó, I., Flores-Meraz, P. L., Randazzo, W., Sánchez, G., López-Rubio, A. y Fabra, M. J. (2019). Antiviral activity of alginateoleic acid based coatings incorporating green tea extract on strawberries and raspberries. Food Hydrocolloids, 87, pp. 611-618. https://doi.org/10.1016/j.foodhyd.2018.08.055

Falcó, I., Randazzo, W., Sánchez, G., LópezRubio, A. y Fabra, M. J. (2019). On the use of carrageenan matrices for the development of antiviral ediblecoatings of interest in berries. Food $\mathrm{Hy}$ drocolloids, 92, pp. 74-85. https://doi. org/10.1016/j.foodhyd.2019.01.039

Falcó, I., Randazzo, W., Rodríguez-Díaz, J., Gozalbo-Rovira, R., Luque, D., Aznar, R. y Sánchez, G. (2019). Antiviral activity of aged green tea extract in model food systems and under gastric conditions. International Journal of Food Microbiology, 292, pp. 101-106. https://doi. org/10.1016/j.ijfoodmicro.2018.12.019

Falcó, I., Randazzo, W., Gómez-Mascaraque, L. G., Aznar, R., López-Rubio, A. y Sánchez, G. (2018). Fostering the an- tiviral activity of green tea extract for sanitizing purposes through controlled storage conditions. Food Control, 84, pp. 485-492. https://doi.org/10.1016/j. foodcont.2017.08.037

Fernandez-Cassi, X., Timoneda, N., Gonzales-Gustavson, E., Abril, J. F., Bofill-Mas, S. y Girones, R. (2017). A metagenomic assessment of viral contamination on fresh parsley plants irrigated with fecally tainted river water. International Journal of Food Microbiology, 257, pp. 80-90. https://doi.org/10.1016/j.ijfoodmicro.2017.06.001

Fraisse, A., Coudray-Meunier, C., MartinLatil, S., Hennechart-Collette, C., Delannoy, S., Fach, P. y Perelle, S. (2017). Digital RT-PCR method for hepatitis A virus and norovirus quantification in soft berries. International Journal of Food Microbiology, 243, pp. 36-45. https://doi. org/10.1016/j.ijfoodmicro.2016.11.022

Fraisse, A., Niveau, F., Hennechart-Collette, C., Coudray-Meunier, C., Martin-Latil, S. y Perelle, S. (2018). Discrimination of infectious and heat-treated norovirus by combining platinum compounds and real-time RT-PCR. International Journal of Food Microbiology, 269, pp. 64-74. https://doi.org/10.1016/j.ijfoodmicro.2018.01.015

Fuster, N., Pintó, R. M., Fuentes, C., Beguiristain, N., Bosch, A. y Guix, S. (2016). Propidium monoazide RTqPCR assays for the assessment of hepatitis A inactivation and for a better estimation of the health risk of contaminated waters. Water Research, 101, pp. 226-232. https:// doi.org/10.1016/j.watres.2016.05.086

Joshi, S. S., Su, X. y D’Souza, D. H. (2015). Antiviral effects of grape seed extract against feline calicivirus, murine norovirus, and hepatitis A virus in model food systems and under gastric conditions. Food Microbiology, 52, pp. 1-10. https://doi. org/10.1016/j.fm.2015.05.011

Kupferschmidt, K. (2016). Europe's new hepatitis problem. Science, 353 (6302), pp. 862-863. https://doi.org/10.1126/ science.353.6302.862

Li, D., Baert, L., Zhang, D., Xia, M., Zhong, W., Van Coillie, E., Jiang, X. y Uyttendaele, M. (2012). Effect of grape seed extract on human norovirus GII.4 and murine norovirus 1 in viral suspensions, on stainless steel discs, and in lettuce wash water. Applied and Environmental Microbiology, 78 (21), pp. 7572-7578. https://doi.org/10.1128/AEM.01987-12
López-Gálvez, F., Randazzo, W., Vásquez, A., Sánchez, G., Tombini Decol, L., Aznar, R., Gil, M. I. y Allende, A. (2018). Irrigating Lettuce with Wastewater Effluent: Does Disinfection with Chlorine Dioxide Inactivate Viruses? Journal of Environmental Quality, 47 (5), pp. 1139-1145. https:// doi.org/10.2134/jeq2017.12.0485

Lowther, J. A., Bosch, A., Butot, S., Ollivier, J., Mäde, D., Rutjes, S. A., Hardouin, G., Lombard, B., in't Veld, P. y Leclercq, A. (2019). Validation of ISO method 15216 part 1 - Quantification of hepatitis A virus and norovirus in food matrices. International Journal of Food Microbiology, 288, pp. 82-90. https://doi. org/10.1016/j.ijfoodmicro.2017.11.014

Moreno, L., Aznar, R. y Sánchez, G. (2015). Application of viability PCR to discriminate the infectivity of hepatitis $A$ virus in food samples. International Journal of Food Microbiology, 201, pp. 1-6. https://doi.org/10.1016/j.ijfoodmicro.2015.02.012

Nieuwenhuijse, D. F. y Koopmans, M. P. G. (2017). Metagenomic sequencing for surveillance of food- and waterborne viral diseases. Frontiers in Microbiology, 8, 230. https://doi.org/10.3389/ fmicb. 2017.00230

Park, E. J., Kim, K. H., Abell, G. C. J., Kim, M. S., Roh, S. W. y Bae, J. W. (2011). Metagenomic analysis of the viral communities in fermented foods. Applied and Environmental Microbiology, 77 (4), pp. 1284-1291. https://doi.org/10.1128/ AEM.01859-10

Persson, S., Eriksson, R., Lowther, J., Ellström, P. y Simonsson, M. (2018). Comparison between RT droplet digital PCR and RT real-time PCR for quantification of noroviruses in oysters. International Journal of Food Microbiology, 284, pp. 73-83. https://doi.org/10.1016/j.ijfoodmicro.2018.06.022

Prevost, B., Goulet, M., Lucas, F. S., Joyeux, M., Moulin, L. y Wurtzer, S. (2016). Viral persistence in surface and drinking water: Suitability of PCR pretreatment with intercalating dyes. Water Research, 91, pp. 68-76. https://doi. org/10.1016/j.watres.2015.12.049

Randazzo, W., D'Souza, D. H. y Sanchez, G. (2018). Norovirus: The Burden of the Unknown. En Rodriguez-Lazaro, D. (ed.) Advances in Food and Nutrition Research (vol. 86). Academic Press, pp. 13-53. 
Randazzo, W., Fabra, M. J., Falcó, I., LópezRubio, A. y Sánchez, G. (2018). Polymers and Biopolymers with Antiviral Activity: Potential Applications for Improving Food Safety. Comprehensive Reviews in Food Science and Food Safety, 17 (3), pp. 754-768. https://doi. org/10.1111/1541-4337.12349

Randazzo, W., Falcó, I., Aznar, R. y Sánchez, G. (2017). Effect of green tea extract on enteric viruses and its application as natural sanitizer. Food Microbiology, 66, pp. 150-156. https://doi.org/10.1016/j. fm.2017.04.018

Randazzo, W., Khezri, M., Ollivier, J., Le Guyader, F. S., Rodríguez-Díaz, J., Aznar, R. y Sánchez, G. (2018). Optimization of PMAxx pretreatment to distinguish between human norovirus with intact and altered capsids in shellfish and sewage samples. International Journal of Food Microbiology, 266, pp. 1-7. https://doi.org/10.1016/j.ijfoodmicro.2017.11.011

Randazzo, W., Vasquez-García, A., Aznar, R. y Sánchez, G. (2018). Viability RT-qPCR to distinguish between HEV and HAV with intact and altered capsids. Fron- tiers in Microbiology, 9, 1973. https:// doi.org/10.3389/fmicb.2018.01973

Ricci, A., Allende, A., Bolton, D., Chemaly, M., Davies, R., Fernandez Escamez, P. S. [...] y Girones, R. (2017). Public health risks associated with hepatitis $E$ virus (HEV) as a food-borne pathogen. EFSA Journal, 15 (7), e04886. https://doi. org/10.2903/j.efsa.2017.4886

Sánchez, G. (2015). Processing Strategies to Inactivate Hepatitis A Virus in Food Products: A Critical Review. Comprehensive Reviews in Food Science and Food Safety, 14 (6), pp. 771-784. https://doi. org/10.1111/1541-4337.12154

Sánchez, G., Elizaquível, P. y Aznar, R. (2012). Discrimination of Infectious Hepatitis A Viruses by Propidium Monoazide RealTime RT-PCR. Food and Environmental Virology, 4 (1), pp. 21-25. https://doi. org/10.1007/s12560-011-9074-5

Varela, M. F., Monteiro, S., Rivadulla, E., Santos, R. y Romalde, J. L. (2018). Development of a novel digital RT-PCR method for detection of human sapovirus in different matrices. Journal of Virological Methods, 254, pp. 21-24. https://doi. org/10.1016/j.jviromet.2018.01.005
Yang, Z., Mammel, M., Papafragkou, E., Hida, K., Elkins, C. A. y Kulka, M. (2017). Application of next generation sequencing toward sensitive detection of enteric viruses isolated from celery samples as an example of produce. International Journal of Food Microbiology, 261, pp. 73-81. https://doi.org/10.1016/j.ijfoodmicro.2017.07.021

\section{Recursos en línea}

ISO 15216-1:2017. Microbiology of the Food Chain - Horizontal Method for Determination of Hepatitis A Virus and Norovirus Using Real-time RT-PCR Part 1: Method for Quantification. [En línea]. Disponible en https://www.iso. org/obp/ui/\#iso:std:iso:15216:-1:ed1:v1:en

World Health Organization. WHO estimates of the global burden of foodborne diseases. Foodborne diseases burden epidemiology reference group 20072015. [En línea]. Disponible en https:// apps.who.int/iris/bitstream/handle/10665/199350/9789241565165_ eng.pdf?sequence $=1$ 